\title{
IAEA coordinated research project on nuclear data for charged-particle monitor reactions and medical isotope production
} \author{
Ferenc T. Tárkányi ${ }^{17}$, and Marco Verpelli ${ }^{1}$ \\ 1 NAPC-Nuclear Data Section, International Atomic Energy Agency, Vienna, Austria \\ 2 University of Surrey, Guildford, UK \\ ${ }^{3}$ Los Alamos National Laboratory (LANL), USA \\ ${ }^{4}$ Instituto Tecnológico de Aeronáutica, Brazil \\ 5 Vrije Universiteit, Brussels, Belgium \\ 6 Government College University, Lahore, Pakistan \\ 7 Institute of Physics and Power Engineering (IPPE), Obninsk, Russia \\ 8 Laboratoire National Henri Becquerel (LNHB), CEA Saclay, France \\ 9 Australian National University (ANU), Canberra, Australia \\ ${ }^{10}$ Kyungpook National University, Republic of Korea \\ 11 Argonne National Laboratory (ANL), USA \\ 12 Nuclear Physics Institute, Rez, Czech Republic \\ 13 National Institute of Physics and Nuclear Engineering "Horia Hulubei”, Romania \\ 14 Bhabha Atomic Research Centre (BARC), Trombay, Mumbai, India \\ 15 Japan Atomic Energy Agency (JAEA), Tokaimura Naka, Ibaraki-ken, Japan \\ 16 Forschungszentrum Jülich (FZJ), Germany \\ 17 Institute of Nuclear Research, Debrecen, Hungary
}

Roberto Capote $^{1, \text { a }}$, Alan L. Nichols ${ }^{2}$, Francois Meiring Nortier ${ }^{3}$, Brett V. Carlson ${ }^{4}$, Jonathan W. Engle ${ }^{3}$, Alex Hermanne ${ }^{5}$ Mazhar Hussain $^{6}$, Anatoly V. Ignatyuk ${ }^{7}$, Mark A. Kellett ${ }^{8}$, Tibor Kibédi ${ }^{9}$, Guinyun Kim ${ }^{10}$, Filip G. Kondev ${ }^{11}$, Ondrej Lebeda ${ }^{12}$, Aurelian Luca ${ }^{13}$, Haladhara Naik ${ }^{14}$, Yasuki Nagai ${ }^{15}$, Ingo Spahn ${ }^{16}$, Saraswatula V. Suryanarayana ${ }^{14}$,

\begin{abstract}
An IAEA coordinated research project was launched in December 2012 to establish and improve the nuclear data required to characterise charged-particle monitor reactions and extend data for medical radionuclide production. An international team was assembled to undertake work addressing the requirements for more accurate cross-section data over a wide range of targets and projectiles, undertaken in conjunction with a limited number of measurements and more extensive evaluations of the decay data of specific radionuclides. These studies are nearing completion, and are briefly described below.
\end{abstract}

\section{Introduction}

One important aspect of IAEA work is to assist all member states in the peaceful application of nuclear science, of which one significant area is disease prevention/control particularly with respect to the efficacious adoption of diagnostic and therapeutic radionuclides in nuclear medicine and radiotherapy. The production routes and decay properties of all such radionuclides need to be well defined, but deficiencies exist, especially with respect to the optimum production of specific radionuclides, minimization/elimination of impurities, and adequate determination of various decay parameters (e.g., halflife, and alpha-particle, electron, positron, gamma-ray and $\mathrm{X}$-ray emission probabilities).

Following on from two earlier Coordinated Research Projects (CRP) on "Charged Particle Cross-Section Database for Medical Radioisotope Production: Diagnostic Radioisotopes and Monitor Reactions" [1] and "Nuclear

a e-mail: Roberto.CapoteNoy@iaea.org
Data for the Production of Therapeutic Radionuclides" [2], the IAEA-NDS has sponsored various consultants' meetings to discuss possible nuclear data requirements up to approximately 2025 [3-5]. Specific recommendations from these three consultants' meetings were brought together to formulate and agree the scope, work programme and deliverables of a Coordinated Research Project designed to focus on further improvements to specific charged-particle monitor reactions and nuclear data for medical radionuclides. Research coordination meetings have been held at regular intervals at the IAEA Headquarters, with the third and final taking place from 30 May to 3 June 2016 at which agreement was reached concerning the closure of this ambitious exercise in 2017 [6-8].

\section{Coordinated nuclear data studies for nuclear medicine applications}

As outlined earlier [9], continued developments in imaging techniques along with improved diagnostic and therapeutic

(C) The Authors, published by EDP Sciences. This is an Open Access article distributed under the terms of the Creative Commons Attribution License 4.0 (http://creativecommons.org/licenses/by/4.0/). 
procedures have encouraged the concomitant evolution and expansion of databases dedicated to the assembly of recommended atomic and nuclear parameters for medical applications, e.g., recommended cross sections and expected yields for production of many therapeutic radionuclides are available from:

www-nds.iaea.org/radionuclides/

The various nuclear data needs and relevant activities within the CRP are described below with respect to reassessments of the existing data within the database and more significant additions that are in the process of being made. See also Table 1.

\subsection{Monitor reactions}

Many of the radionuclides under consideration are produced from the nuclear reactions of charged-particle beams with well-defined targets within cyclotrons and various other forms of accelerator. A major problem in such an experimental arrangement is the quantification of the charged-particle flux, which is best addressed via a monitor reaction of well-known cross section in the energy range of interest. Thus, specific monitor reactions are commonly used to determine reliable beam fluxes in all forms of cross-section measurement, and need to be defined with confidence.

All of the monitor reactions quantified originally in IAEA-TECDOC-1211 were judged to require a rigorous quantification of their uncertainties along with covariances as a function of beam energy. Thus, emphasis during the course of the CRP was placed on either assessments or re-assessments of the excitation function data and uncertainties for the generation of ${ }^{22} \mathrm{Na},{ }^{24} \mathrm{Na},{ }^{46} \mathrm{Sc},{ }^{48} \mathrm{~V}$, ${ }^{51} \mathrm{Cr},{ }^{56} \mathrm{Co},{ }^{58} \mathrm{Co},{ }^{57} \mathrm{Ni},{ }^{61} \mathrm{Cu},{ }^{62} \mathrm{Zn},{ }^{63} \mathrm{Zn},{ }^{65} \mathrm{Zn},{ }^{66} \mathrm{Ga}$, ${ }^{67} \mathrm{Ga}$ and ${ }^{96 \mathrm{~g}+\mathrm{m}} \mathrm{Tc}$, while more significantly these studies were coupled with new cross-section measurements for the production of ${ }^{46} \mathrm{Sc},{ }^{48} \mathrm{~V},{ }^{56} \mathrm{Co},{ }^{58} \mathrm{Co},{ }^{62} \mathrm{Zn},{ }^{63} \mathrm{Zn},{ }^{65} \mathrm{Zn}$, ${ }^{66} \mathrm{Ga},{ }^{67} \mathrm{Ga}$ and ${ }^{96 \mathrm{~g}+\mathrm{m}} \mathrm{Tc}$. Full decay-scheme evaluations were also requested for ${ }^{61} \mathrm{Cu},{ }^{62} \mathrm{Zn}$ and ${ }^{63} \mathrm{Zn}$, although this requirement for recommended ${ }^{62} \mathrm{Zn}$ decay data was not addressed directly during the course of the CRP.

\subsection{Diagnostic $\gamma$ emitters}

Reactor production of ${ }^{99} \mathrm{Mo} /{ }^{99 m} \mathrm{Tc}$ generators has been the long-term popular means of producing the most commonly used $\gamma$-ray emitting radionuclide for diagnostic purposes, and both the necessary fission-yield and decay data are well known. Nevertheless, new data requirements have arisen as a consequence of recent efforts to produce this radionuclide by means of charged-particle accelerators rather than fission reactors. Various neutron-, proton-, deuteron-, photofission- and photoneutron-induced reactions need to be studied experimentally, along with the necessary series of subsequent assessments or reassessments. Furthermore, cross-section measurements and evaluations were requested for the production of ${ }^{51} \mathrm{Cr}$ (but of uncertain merit as a diagnostic $\gamma$ emitter) and ${ }^{64} \mathrm{Cu}$ along with re-assessments of the excitation functions for specific reactions to produce ${ }^{51} \mathrm{Cr},{ }^{111} \mathrm{In}$, ${ }^{121} \mathrm{I},{ }^{123} \mathrm{Cs},{ }^{123} \mathrm{Xe},{ }^{200} \mathrm{~Pb},{ }^{201} \mathrm{~Pb}$ and ${ }^{202 \mathrm{~m}} \mathrm{~Pb}$, primarily desired as products but also some related impurities. However, the experimental studies of ${ }^{\text {nat }} \mathrm{W}(\alpha, \mathrm{x}){ }^{186,188} \mathrm{Re}$ reactions furnished low cross-section data such that no recommendations proved forthcoming.
Detailed Auger-electron decay data were requested for ${ }^{99 \mathrm{~m}} \mathrm{Tc}$ and ${ }^{111} \mathrm{In}$.

\subsection{Diagnostic $\beta^{+}$emitters}

\subsubsection{Directly produced $\boldsymbol{\beta}^{+}$emitters}

Significant requirements exist for the re-assessment of the excitation functions for the production of ${ }^{55} \mathrm{Co},{ }^{61} \mathrm{Cu}$, ${ }^{66} \mathrm{Ga},{ }^{68} \mathrm{Ga},{ }^{72} \mathrm{As},{ }^{73} \mathrm{Se},{ }^{76} \mathrm{Br},{ }^{86} \mathrm{Y},{ }^{89} \mathrm{Zr},{ }^{90} \mathrm{Nb},{ }^{94 \mathrm{~m}} \mathrm{Tc},{ }^{110 \mathrm{~m}} \mathrm{In}$ and ${ }^{120} \mathrm{I}$, coupled with the need for new cross-section measurements of ${ }^{n a t} \mathrm{Fe}(\mathrm{p}, \mathrm{x}){ }^{55} \mathrm{Co},{ }^{61} \mathrm{Ni}(\mathrm{p}, \mathrm{n}){ }^{61} \mathrm{Cu},{ }^{64} \mathrm{Zn}$ $(\mathrm{p}, \alpha){ }^{61} \mathrm{Cu},{ }^{68} \mathrm{Zn}(\mathrm{p}, \mathrm{n}){ }^{68} \mathrm{Ga}$, ${ }^{\text {nat }} \mathrm{Ge}(\mathrm{p}, \mathrm{xn}){ }^{72} \mathrm{As},{ }^{75} \mathrm{As}(\mathrm{p}, 3 \mathrm{n})$ ${ }^{73} \mathrm{Se},{ }^{76} \mathrm{Se}(\mathrm{p}, \mathrm{n}){ }^{76} \mathrm{Br},{ }^{77} \mathrm{Se}(\mathrm{p}, 2 \mathrm{n}){ }^{76} \mathrm{Br},{ }^{89} \mathrm{Y}(\mathrm{d}, 2 \mathrm{n}){ }^{89} \mathrm{Zr},{ }^{93} \mathrm{Nb}$ $(\mathrm{p}, \mathrm{x}){ }^{90} \mathrm{Nb},{ }^{89} \mathrm{Y}(\alpha, \mathrm{x}){ }^{90} \mathrm{Nb}$ and other reactions.

Decay-scheme evaluations were requested for ${ }^{52} \mathrm{Fe}$, ${ }^{64} \mathrm{Cu},{ }^{66} \mathrm{Ga},{ }^{72} \mathrm{As},{ }^{73} \mathrm{Se},{ }^{76} \mathrm{Br},{ }^{86} \mathrm{Y},{ }^{89} \mathrm{Zr},{ }^{94 \mathrm{~m}} \mathrm{Tc}$ and ${ }^{120} \mathrm{I}$, along with the recommended half-life for ${ }^{44} \mathrm{Ti}$; however, the requirement for a full evaluation of the ${ }^{72} \mathrm{As}$ decay data was not addressed during the course of the CRP. At a later stage in the work, full decay-scheme evaluations were also requested and undertaken for ${ }^{52} \mathrm{Mn}$ and ${ }^{52 \mathrm{~m}} \mathrm{Mn}$ as the important daughters of ${ }^{52} \mathrm{Fe}$ [11].

\subsection{2. $\boldsymbol{\beta}^{+}$generators}

Generator systems for the production of suitable $\beta^{+}$emitters were also considered. Measurements and assessments of the cross sections were judged to be required for the following parent radionuclides:

$\begin{aligned}- & { }^{52} \mathrm{Fe} /{ }^{52 m} \mathrm{Mn}: \quad{ }^{55} \mathrm{Mn}(\mathrm{p}, 4 \mathrm{n}){ }^{52} \mathrm{Fe}, \quad{ }^{\text {nat }} \mathrm{Ni}(\mathrm{p}, \mathrm{x}){ }^{52} \mathrm{Fe} \text { and } \\ & { }^{50} \mathrm{Cr}(\alpha, 2 \mathrm{n})^{52} \mathrm{Fe} \text { reactions (all assess only), } \\ - & { }^{62} \mathrm{Zn} /{ }^{62} \mathrm{Cu}:{ }^{63} \mathrm{Cu}(\mathrm{p}, 2 \mathrm{n})^{62} \mathrm{Zn} \text { (measure and assess) and } \\ & { }^{63} \mathrm{Cu}(\mathrm{d}, 3 \mathrm{n}){ }^{62} \mathrm{Zn} \text { reactions (assess only), } \\ - & { }^{68} \mathrm{Ge} /{ }^{68} \mathrm{Ga}:{ }^{\text {nat }} \mathrm{Ga}(\mathrm{p}, \mathrm{xn}){ }^{68} \mathrm{Ge},{ }^{69} \mathrm{Ga}(\mathrm{p}, 2 \mathrm{n}){ }^{68} \mathrm{Ge} \text { and } \\ & { }^{71} \mathrm{Ga}(\mathrm{p}, 4 \mathrm{n}){ }^{68} \mathrm{Ge} \text { reactions (all measure and assess), } \\ - & { }^{72} \mathrm{Se} /{ }^{72} \mathrm{As}:{ }^{75} \mathrm{As}(\mathrm{p}, 4 \mathrm{n}){ }^{72} \mathrm{Se} \text { and nat } \mathrm{Br}(\mathrm{p}, \mathrm{x}){ }^{72} \mathrm{Se} \text { reactions } \\ & (\text { all assess only), } \\ - & { }^{82} \mathrm{Sr} /{ }^{82} \mathrm{Rb}:{ }^{n a t} \mathrm{Rb}(\mathrm{p}, \mathrm{xn}){ }^{82} \mathrm{Sr} \text { and }{ }^{85} \mathrm{Rb}(\mathrm{p}, 4 \mathrm{n})^{82} \mathrm{Sr} \text { reac- } \\ & \text { tions (all assess only), }\end{aligned}$

while re-assessments of the available cross-section data were judged to be necessary for all of the main reactions leading to ${ }^{44} \mathrm{Ti} /{ }^{44} \mathrm{Sc},{ }^{110} \mathrm{Sn} /{ }^{10 \mathrm{~m}} \mathrm{In},{ }^{118} \mathrm{Te} /{ }^{118} \mathrm{Sb}$, ${ }^{122} \mathrm{Xe} /{ }^{122} \mathrm{I},{ }^{128} \mathrm{Ba} /{ }^{128} \mathrm{Cs}$ and ${ }^{140} \mathrm{Nd} /{ }^{140} \mathrm{Pr}$ generators. The ${ }^{71} \mathrm{Ga}(\mathrm{p}, 4 \mathrm{n}){ }^{68} \mathrm{Ge}$ reaction was subsequently removed from the above list.

\subsection{Therapeutic $\alpha$ emitters}

Assessments of existing measured cross-section data for ${ }^{232} \mathrm{Th}(\mathrm{p}, \mathrm{x})$ production of ${ }^{225} \mathrm{Ra},{ }^{225} \mathrm{Ac}$ and impurity ${ }^{227} \mathrm{Ac}$, and ${ }^{226} \mathrm{Ra}(\mathrm{p}, 2 \mathrm{n})$ production of ${ }^{225} \mathrm{Ac}$ were recommended.

Identical demands were also made concerning ${ }^{230} \mathrm{U}$ production from the ${ }^{231} \mathrm{~Pa}(\mathrm{p}, 2 \mathrm{n}),{ }^{231} \mathrm{~Pa}(\mathrm{~d}, 3 \mathrm{n})$ and $\left.{ }^{232} \mathrm{Th}(\mathrm{p}, 3 \mathrm{n}){ }^{230} \mathrm{~Pa}\left(\beta^{-}\right)\right)^{230} \mathrm{U}$ reactions, and the ${ }^{232} \mathrm{Th}$ $(\mathrm{p}, \mathrm{x})^{227} \mathrm{Th}$ reaction to initiate the ${ }^{227} \mathrm{Th}(\alpha)^{223} \operatorname{Ra}(\alpha)$ decay chain.

Full decay-scheme evaluations were requested for all radionuclides constituting the ${ }^{230} \mathrm{U}$ decay chain: ${ }^{230} \mathrm{U}(\alpha)^{226} \mathrm{Th}(\alpha)^{222} \operatorname{Ra}(\alpha){ }^{218} \operatorname{Rn}(\alpha)^{214} \operatorname{Po}(\alpha)^{210} \mathrm{~Pb}\left(\beta^{-}\right)^{210} \mathrm{Bi}$ $\left(\beta^{-}\right)^{210} \mathrm{Po}(\alpha)^{206} \mathrm{~Pb}$ (stable). 
Table 1. Charged-particle monitor reactions and medical radionuclide: CRP activities beyond earlier studies (IAEA-TECDOC-1211 [1] and IAEA Technical Reports Series No. 473 [2]).

\begin{tabular}{|c|c|c|}
\hline & Cross-section measurements and/or evaluations & $\begin{array}{l}\text { Decay data } \\
\text { evaluations }\end{array}$ \\
\hline Monitor reactions & 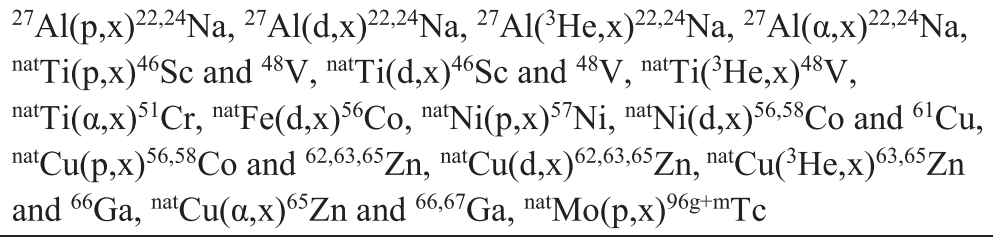 & ${ }^{61} \mathrm{Cu},{ }^{63} \mathrm{Zn}$ \\
\hline Diagnostic $\gamma$ emitters & $\begin{array}{l}{ }^{\mathrm{nat}} \mathrm{Ti}(\alpha . \mathrm{x}){ }^{51} \mathrm{Cr},{ }^{\mathrm{nat}} \mathrm{V}(\mathrm{p}, \mathrm{n}){ }^{51} \mathrm{Cr},{ }^{\mathrm{nat}} \mathrm{V}(\mathrm{d}, \mathrm{xn}){ }^{51} \mathrm{Cr},{ }^{\text {nat }} \mathrm{Mn}(\mathrm{p}, \mathrm{x}){ }^{51} \mathrm{Cr}, \\
{ }^{{ }^{n a t}} \mathrm{Fe}(\mathrm{p}, \mathrm{x}){ }^{51} \mathrm{Cr},{ }^{64} \mathrm{Zn}(\mathrm{n}, \mathrm{p}){ }^{64} \mathrm{Cu},{ }^{100} \mathrm{Mo}(\mathrm{n}, 2 \mathrm{n}){ }^{99} \mathrm{Mo},{ }^{100} \mathrm{Mo}(\mathrm{p}, 2 \mathrm{n}){ }^{99 \mathrm{~g}+\mathrm{m}} \mathrm{Tc}, \\
\left.{ }^{100} \mathrm{Mo}(\mathrm{p}, \mathrm{pn})\right)^{99} \mathrm{Mo},{ }^{100} \mathrm{Mo}(\mathrm{d}, 3 \mathrm{n}){ }^{99 \mathrm{~g}+\mathrm{m}} \mathrm{Tc},{ }^{100} \mathrm{Mo}(\mathrm{d}, 2 \mathrm{pn}){ }^{99} \mathrm{Mo}, \\
{ }^{100} \mathrm{Mo}(\gamma, \mathrm{n}){ }^{99} \mathrm{Mo},{ }^{238} \mathrm{U}(\gamma, \mathrm{f}){ }^{99} \mathrm{Mo},{ }^{112} \mathrm{Cd}(\mathrm{p}, 2 \mathrm{n}){ }^{111} \mathrm{In},{ }^{124} \mathrm{Xe}(\mathrm{p}, \mathrm{x}){ }^{121} \mathrm{I}, \\
{ }^{124} \mathrm{Xe}(\mathrm{p}, 2 \mathrm{n}){ }^{123} \mathrm{Cs},{ }^{124} \mathrm{Xe}(\mathrm{p}, \mathrm{pn}){ }^{123} \mathrm{Xe},{ }^{203} \mathrm{Tl}(\mathrm{p}, 2 \mathrm{n}){ }^{202 \mathrm{~m}} \mathrm{~Pb}, \\
{ }^{203} \mathrm{Tl}(\mathrm{p}, 3 \mathrm{n}){ }^{201} \mathrm{~Pb},{ }^{203} \mathrm{Tl}(\mathrm{p}, 4 \mathrm{n}){ }^{200} \mathrm{~Pb}\end{array}$ & $\begin{array}{l}{ }^{99} \mathrm{Mo} /{ }^{99 \mathrm{~m}} \mathrm{Tc}, \\
\text { pure }{ }^{99 \mathrm{~m}} \mathrm{Tc}, \\
{ }^{111} \mathrm{In}\end{array}$ \\
\hline $\begin{array}{l}\text { Directly produced } \\
\qquad \beta^{+} \text {emitters }\end{array}$ & 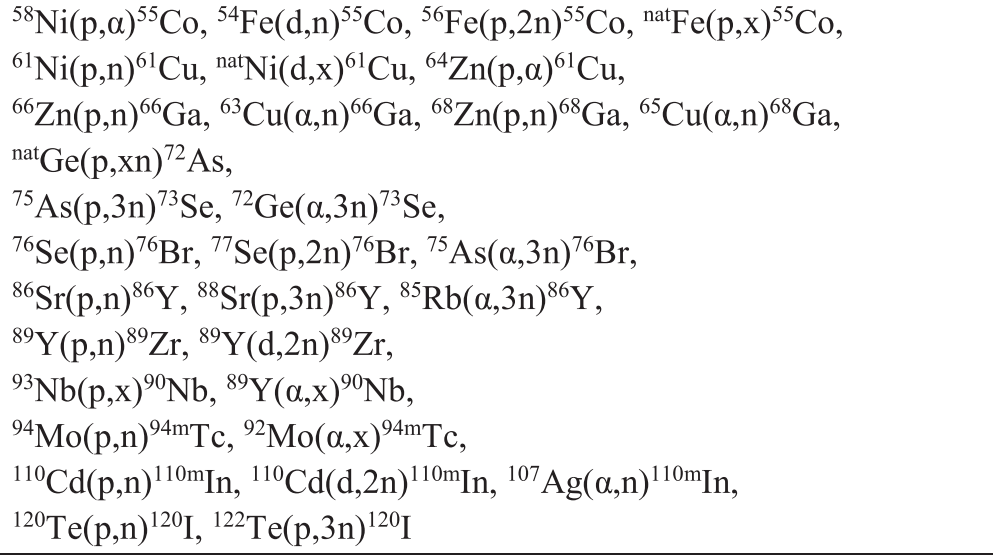 & $\begin{array}{l}{ }^{64} \mathrm{Cu},{ }^{66} \mathrm{Ga}^{\#}, \\
{ }^{73} \mathrm{Se},{ }^{76} \mathrm{Br}, \\
{ }^{86} \mathrm{Y},{ }^{89} \mathrm{Zr}, \\
{ }^{94 \mathrm{~m}} \mathrm{Tc},{ }^{120} \mathrm{I}\end{array}$ \\
\hline Generator $\boldsymbol{\beta}^{+}$emitters & $\begin{array}{l}{ }^{52} \mathrm{Fe} /{ }^{52 \mathrm{~m}} \mathrm{Mn}:{ }^{55} \mathrm{Mn}(\mathrm{p}, 4 \mathrm{n}){ }^{52} \mathrm{Fe},{ }^{\text {nat }} \mathrm{Ni}(\mathrm{p}, \mathrm{x}){ }^{52} \mathrm{Fe},{ }^{50} \mathrm{Cr}(\alpha, 2 \mathrm{n}){ }^{52} \mathrm{Fe} \\
{ }^{6} \mathrm{Zn} /{ }^{62} \mathrm{Cu}:{ }^{63} \mathrm{Cu}(\mathrm{p}, 2 \mathrm{n}){ }^{62} \mathrm{Zn},{ }^{63} \mathrm{Cu}(\mathrm{d}, 3 \mathrm{n}){ }^{62} \mathrm{Zn} \\
{ }^{68} \mathrm{Ge} /{ }^{68} \mathrm{Ga}:{ }^{n a t} \mathrm{Ga}(\mathrm{p}, \mathrm{xn}){ }^{68} \mathrm{Ge},{ }^{69} \mathrm{Ga}(\mathrm{p}, 2 \mathrm{n}){ }^{68} \mathrm{Ge} \\
{ }^{72} \mathrm{Se} /{ }^{72} \mathrm{As}:{ }^{75} \mathrm{As}(\mathrm{p}, 4 \mathrm{n}){ }^{72} \mathrm{Se},{ }^{\text {nat }} \mathrm{Br}(\mathrm{p}, \mathrm{x}){ }^{72} \mathrm{Se} \\
{ }^{82} \mathrm{Sr} /{ }^{82} \mathrm{Rb}:{ }^{\text {nat }} \mathrm{Rb}(\mathrm{p}, \mathrm{xn}){ }^{82} \mathrm{Sr},{ }^{85} \mathrm{Rb}(\mathrm{p}, 4 \mathrm{n}){ }^{82} \mathrm{Sr} \\
{ }^{44} \mathrm{Ti} /{ }^{44} \mathrm{Sc},{ }^{110} \mathrm{Sn} /{ }^{110 \mathrm{~m}} \mathrm{In},{ }^{118} \mathrm{Te} /{ }^{118} \mathrm{Sb},{ }^{122} \mathrm{Xe} /{ }^{122} \mathrm{I},{ }^{128} \mathrm{Ba} /{ }^{128} \mathrm{Cs} \text { and } \\
{ }^{140} \mathrm{Nd} /{ }^{140} \mathrm{Pr}: \text { studies undertaken of all main reactions leading to parent } \\
\text { nuclide }\end{array}$ & $\begin{array}{l}{ }^{44} \mathrm{Ti}\left(\mathrm{t}_{1} / 2\right), \\
{ }^{52} \mathrm{Fe} /{ }^{52 \mathrm{~m}} \mathrm{Mn} \\
\text { and }{ }^{52} \mathrm{Mn}\end{array}$ \\
\hline Therapeutic $\alpha$ emitters & $\begin{array}{l}{ }^{229} \mathrm{Th}(\alpha){ }^{225} \mathrm{Ra}\left(\beta^{-}\right){ }^{225} \mathrm{Ac}(\alpha) \text { decay chain to }{ }^{213} \mathrm{Bi}: \\
{ }^{232} \mathrm{Th}(\mathrm{p}, \mathrm{x}){ }^{225} \mathrm{Ra} \text { and }{ }^{225,227} \mathrm{Ac},{ }^{226} \mathrm{Ra}(\mathrm{p}, 2 \mathrm{n}){ }^{225} \mathrm{Ac} \\
{ }^{230} \mathrm{U}(\alpha){ }^{226} \mathrm{Th}(\alpha) \text { decay chain: }{ }^{231} \mathrm{~Pa}(\mathrm{~d}, 3 \mathrm{n}){ }^{230} \mathrm{U},{ }^{231} \mathrm{~Pa}(\mathrm{p}, 2 \mathrm{n}){ }^{230} \mathrm{U}, \\
\left.{ }^{232} \mathrm{Th}(\mathrm{p}, 3 \mathrm{n}){ }^{230} \mathrm{~Pa}\left(\beta^{-}\right)\right)^{230} \mathrm{U} \\
{ }^{227} \mathrm{Th}(\alpha){ }^{223} \mathrm{Ra}(\alpha) \text { decay chain: }{ }^{232} \mathrm{Th}(\mathrm{p}, \mathrm{x}){ }^{227} \mathrm{Th}\end{array}$ & $\begin{array}{l}{ }^{230} \mathrm{U} \text { decay } \\
\text { chain }\end{array}$ \\
\hline $\begin{array}{l}\text { Therapeutic electron } \\
\text { and X-ray emitters }\end{array}$ & 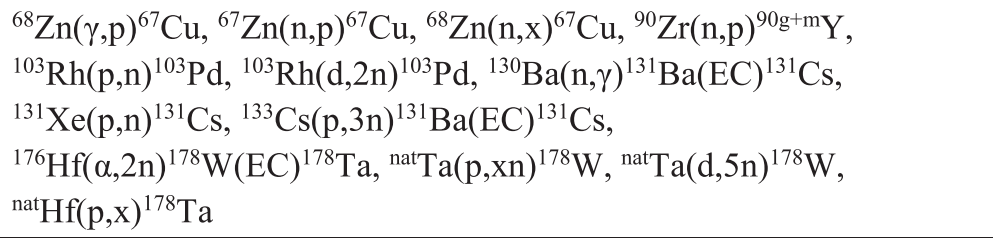 & $\begin{array}{l}{ }^{67} \mathrm{Cu}^{*},{ }^{99 \mathrm{~m}} \mathrm{Tc}, \\
{ }^{103} \mathrm{Pd},{ }^{111} \mathrm{In}, \\
{ }^{125} \mathrm{I},{ }^{131} \mathrm{Cs}, \\
{ }^{178 \mathrm{~g}+\mathrm{m}} \mathrm{Ta}\end{array}$ \\
\hline
\end{tabular}

${ }^{*}$ Measurement of $\gamma$-ray and electron emission probabilities by Chen, et al. [10].

\# On-going measurements of $\gamma$-ray emission probabilities by Kondev, et al. 


\subsection{Therapeutic electron and X-ray emitters}

Assessments of reactions suitable for the direct production of ${ }^{67} \mathrm{Cu},{ }^{90 \mathrm{~g}+\mathrm{m}} \mathrm{Y},{ }^{131} \mathrm{Cs}$ and parent ${ }^{131} \mathrm{Ba}$ were recommended, while measurements and assessments of the production of ${ }^{178} \mathrm{Ta}$ by means of ${ }^{176} \mathrm{Hf}(\alpha, 2 \mathrm{n}){ }^{178} \mathrm{~W}(\mathrm{EC})^{178} \mathrm{Ta}$ and ${ }^{\text {nat }} \mathrm{Hf}(\mathrm{p}, \mathrm{x})$ also needed to be undertaken.

A decay-scheme evaluation was requested for ${ }^{67} \mathrm{Cu}$, and ${ }^{103} \mathrm{Pd}$, along with the accurate derivation of Augerelectron decay data for ${ }^{99 \mathrm{~m}} \mathrm{Tc},{ }^{103} \mathrm{Pd},{ }^{111} \mathrm{In}$ and ${ }^{178} \mathrm{Ta}$. Furthermore, later requests for evaluations of a similar nature for ${ }^{125} \mathrm{I}$ and ${ }^{131} \mathrm{Cs}$ EC decay were also addressed.

Within the context of the CRP studies, comprehensive measurements were made of the absolute $\gamma$-ray and $\beta^{-}$ decay emission probabilities in the decay of ${ }^{67} \mathrm{Cu}$ in order to resolve a significant number of issues involving these particular values and historic lack of information on their uncertainties [10].

\section{Status and impacts}

As described in Sect. 2, the coordinated work programme involved the study and evaluation of an unusually large number of nuclear reactions. While various cross-section measurements and assessments were undertaken at the individual institutes, all such data were collected together at the Institute for Physics and Power Engineering (IPPE), Obninsk, in order to recommend definitive sets of cross-section data with consistent uncertainties and covariances as derived by means of the Pade approximation and UNERRES approach [12]. Examples of these highly prescriptive studies can be found in Figs. 1 and 2 for ${ }^{27} \mathrm{Al}\left({ }^{3} \mathrm{He}, \mathrm{x}\right){ }^{22} \mathrm{Na}$ and ${ }^{\text {nat }} \mathrm{Ga}(\mathrm{p}, \mathrm{x})^{68} \mathrm{Ge}$ reactions, respectively.

${ }^{27} \mathrm{Al}\left({ }^{3} \mathrm{He}, \mathrm{x}\right){ }^{22} \mathrm{Na}$ is a well-known monitor reaction for ${ }^{3} \mathrm{He}$ beams with energies from 8 up to many tens of $\mathrm{MeV}$. The recommended IAEA data of 2001 extended up to $100 \mathrm{MeV}$ [1]. One new dataset was measured within the on-going CRP, and the evaluation was extended up to $130 \mathrm{MeV}$. Good agreement can be seen in Fig. 1 (top panel) between the IAEA recommendations of 2001 (red dashed) and 2016 (black bold). The bottom panel shows the uncertainty quantified by means of UNERRES. Few data sets exist above $70 \mathrm{MeV}$, and UNERRES fails to generate a proper estimate of the uncertainty (see dashed line in the bottom panel). A systematic uncertainty at a level of $4 \%$ was estimated by experts, and combined with the UNERRES results to produce the final uncertainty estimate over the whole energy range. As shown in the bottom panel of Fig.1, the estimated uncertainty increases up to $25 \%$ below $15 \mathrm{MeV}$ and to the reaction threshold.

${ }^{68} \mathrm{Ga}$ is an appropriate radioisotope for certain PET diagnostic procedures, and ${ }^{68} \mathrm{Ge} /{ }^{68} \mathrm{Ga}$ generators are increasingly being used to extract positron-emitting ${ }^{68} \mathrm{Ga}$ from sources of the parent ${ }^{68} \mathrm{Ge}$ isotope which, with a halflife of 271 days, is convenient for in-hospital production and handling.

The recommended excitation function for the generation of parent ${ }^{68} \mathrm{Ge}$ from natural gallium targets by proton irradiation is shown in Fig. 2. Selected experimental data included measurements undertaken by the CRP participants.

All major aspects of many of the individual decay schemes and their data characteristics are well quantified
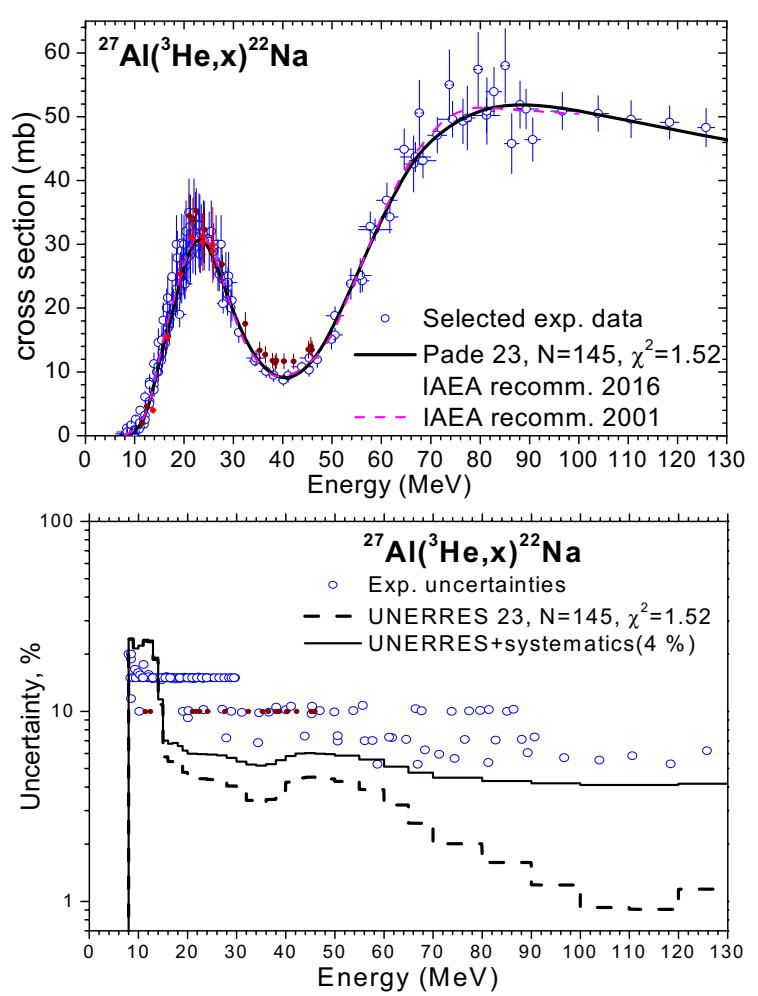

Figure 1. ${ }^{27} \mathrm{Al}\left({ }^{3} \mathrm{He}, \mathrm{x}\right){ }^{22} \mathrm{Na}$ monitor reaction, upper panel: comparison of 2016 and 2001 fits; lower panel: uncertainty estimate of 2016 fit.

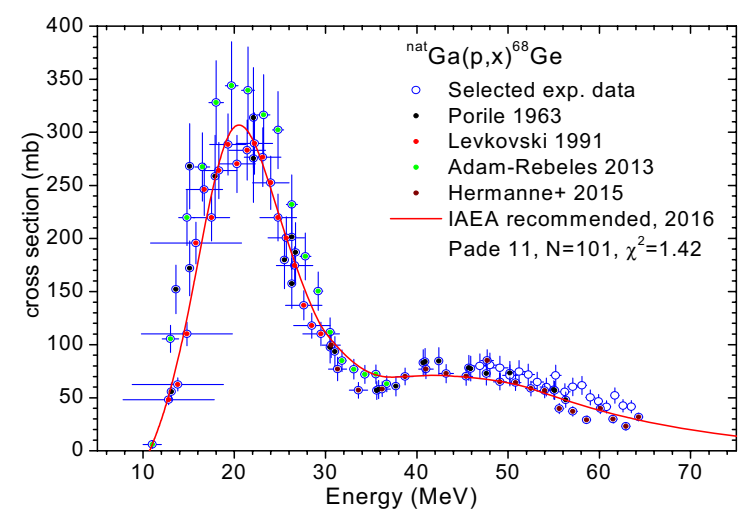

Figure 2. Cross sections for production of ${ }^{68} \mathrm{Ga}$ generator.

even when more detailed features are less confidently known. While any ill-defined decay-data omissions are believed to have modest to small impact on the decay parameters required in the relevant cross-section studies (i.e., half-life, and $\gamma$ and X-ray emission probabilities), they may modify the overall dosimetry implications. Reasonable arguments can be made to undertake further measurements of $\alpha, \beta, \gamma$ and X-ray emissions by direct, coincident and total absorption spectroscopy at improved spectral resolution in order to derive more comprehensive nuclear structure with confidence. For example, the existing evaluations of the complex decay schemes of both ${ }^{76} \mathrm{Br}$ and ${ }^{120} \mathrm{I}$ indicate that our knowledge of their EC decay would benefit greatly from further in-depth $\gamma$ singles and $\gamma-\gamma$ coincidence studies along with total absorption spectroscopy measurements of the $\gamma$ rays (TAS). Confident identification of the ground state of ${ }^{178} \mathrm{Ta}$ was judged to be a problem (whether the $7^{-}$state (half-life of $2.13 \mathrm{~h}$ ), or the $\left(1^{+}\right)$state (half-life of $9.31 \mathrm{~min}$ )) 
that could be addressed by means of suitable Penning trap measurements and more extensive $\gamma$ spectroscopic studies. Other resulting features of the decay-scheme evaluations that merit attention include inconsistencies in the absolute $\gamma$-ray emission probabilities of ${ }^{61} \mathrm{Cu}$ as detected in related cross-section studies, ${ }^{73} \mathrm{Se}$ (multipolarity of $67.039-\mathrm{keV}$ $\gamma$ transition), ${ }^{94 \mathrm{~m}} \mathrm{Tc},{ }^{103} \mathrm{Pd}$ (inconsistencies in measured $\mathrm{X}$ and $\gamma$-ray emissions) and ${ }^{111} \mathrm{In}$ (perceived lack of reliable measurements of the $150.82-$ and $245.39-\mathrm{keV} \gamma$ rays).

An accurate knowledge of the full energy spectrum of the Auger electrons is a crucial step in the development of feasible internal cancer treatment strategies. Unfortunately, Auger-electron rates of the most commonly used radionuclides vary rather significantly $\left({ }^{99 m} \mathrm{Tc},{ }^{111} \mathrm{In},{ }^{125} \mathrm{I}\right.$, etc.), and are judged to be inadequately defined. Decaydata assessments indicate that uncertainties in such data arise because the contributions of the $\mathrm{M}, \mathrm{N}, \mathrm{O}$, etc. atomic shells are commonly ignored in decay-scheme evaluations, even though the energies of the Auger electrons associated with these shells are particularly important for medical applications. Thus, a new physical model has been developed by Lee, et al. [13], which takes the most recent nuclear structure information, internal conversion coefficients and electron capture rates to calculate the initial distribution of electron vacancies, and has been applied to the appropriate radionuclides within the existing CRP. These resulting Auger-electron and X-ray data have also been compared with their equivalent experimental data prior to recommended adoption.

Four separate packages of work will be prepared for publication in the open literature that will focus on the various measurements, extensive assessments and evaluations, along with the recommended data produced in the course of the coordinated research project (CRP): (1) monitor reactions, (2) diagnostic radionuclides, (3) therapeutic radionuclides, and (4) decay data.

\section{Concluding remarks}

The contents of this short paper constitute a brief summary of the agreed activities undertaken by participants in an IAEA coordinated research project dedicated to the derivation of improved cross-section and decay data for radionuclides identified with nuclear medicine, diagnostic procedures and therapeutic applications from late 2012 to the end of 2016. Virtually all of the work defined in Table 1 has been undertaken, or should be completed in 2016. Participants reviewed the recommendations of a series of consultants' meeting at their own research coordination meetings [6-8], and agreed upon joint and individual activities to address a wide range of significant requests for highly pertinent nuclear data.
IAEA staff within the Nuclear Data Section maintains a Web site dedicated to the dissemination of atomic and nuclear data for medical applications. All of the recommended data that have evolved from the CRP described above and earlier relevant CRP activities can be found at the following address:

www-nds. iaea.org/medportal/

All of the work described in this paper represents the outputs from various measurement and evaluation initiatives agreed at the research coordination meetings organized under the auspices of the International Atomic Energy Agency. The authors would like to thank all colleagues at their own research institutes for encouraging their involvement, and staff of the IAEA Nuclear Data Section for preparing for and organizing the coordinated research project. Work at ANL is supported by the U.S. Department of Energy, Office of Science, Office of Nuclear Physics under Contract No. DE-AC02-06CH11357.

\section{References}

[1] Charged particle cross-section database for medical radioisotope production: diagnostic radioisotopes and monitor reactions, IAEA report IAEA-TECDOC-1211, IAEA, Vienna, Austria, 2001

[2] E. Běták, et al., Nuclear data for the production of therapeutic radionuclides, IAEA Technical Reports Series No. 473, Eds: S.M. Qaim, F. Tárkányi, R. Capote, IAEA, Vienna, Austria, 2011, ISBN 97892-0-115010-3

[3] R. Capote, A.L. Nichols, IAEA report INDC(NDS)0535, IAEA, Vienna, Austria, 2008

[4] R. Capote, F.M. Nortier, IAEA report INDC(NDS)0591, IAEA, Vienna, Austria, 2011

[5] A.L. Nichols, S.M. Qaim, R. Capote, IAEA report INDC(NDS)-0596, IAEA, Vienna, Austria, 2011

[6] A.L. Nichols, R. Capote, IAEA report INDC(NDS)0630, IAEA, Vienna, Austria, 2013

[7] A.L. Nichols, F.M. Nortier, R. Capote, IAEA report INDC(NDS)-0675, IAEA, Vienna, Austria, 2015

[8] A.L. Nichols, F.M. Nortier, R. Capote, IAEA report INDC(NDS)-0717, IAEA, Vienna, Austria, 2016

[9] A.L. Nichols, R. Capote, Nucl. Data Sheets 120, 239 (2014)

[10] J. Chen, et al, Phys. Rev. C92, 044330 (2015)

[11] A. Luca, Appl. Radiat. Isot. 109, 169 (2016); A. Luca, this conference (2016)

[12] E.V. Gai, Voprosy Atomnoi Nauki i Tekhniki, ser. Nuclear Constants, issue 1, 56 (2007)

[13] B.Q. Lee, et al., Comput. Math. Methods Med. ID 651475 (2012); B.Q. Lee, T. Kibédi, A.E. Stuchbery, EPJ Web of Conferences 91, 00007 (2015) 